\title{
GRID INTEGRATION OF OFFSHORE WIND FARMS USING MULTI-TERMINAL DC TRANSMISSION SYSTEMS (MTDC)
}

\author{
Giddani O. A ${ }^{(1)}$, Grian. P. Adam ${ }^{(2)}$, O. Anaya-Lara ${ }^{(3),}$ K. L. Lo ${ }^{(4)}$ \\ tjb08132@eee.strath.ac.uk ${ }^{1}$, grain.adam@eee.strath.ac.uk ${ }^{2}$ and olimpo.anaya-lara@eee.strath.ac.uk ${ }^{3}$ \\ Strathclyde University, \\ Electronic and Electrical Engineering Department \\ Royal College Building \\ 204 George Street, Glasgow \\ G1 1XW
}

Keywords: Multi-terminal VSC-HVDC, fixed speed wind turbine generator, reactive power compensation, frequency control.

\begin{abstract}
This paper discusses the control flexibility and fault ridethrough capability of the bi-polar multi-terminal DC transmission system based on voltage source converters used for integration of large-scale offshore wind farms. Issues such as voltage support and short-term frequency stabilization of the AC network utilizing the stored energy in the wind turbine inertia and DC link capacitors are discussed. Regarding control flexibility, two aspects are presented: power sharing between the grid-side converters by any ratio, and provision of an alternative path for the power flow in case of a permanent DC fault or loss of one grid-side converter. In this investigation, the wind farms are based on fixed-speed wind generators, while the converters are modelled as a neutral-point clamped converter using the universal bridge. The investigation was conducted in Matlab/Simulink.
\end{abstract}

\section{Introduction}

Today, wind power plays a major role in meeting the greenhouse emission targets in various countries worldwide. However, the variable nature of the wind resource introduces some difficulties concerning the quality, reliability and availability of the power generated from wind.

Power electronic converters now play a leading role in facilitating the integration of wind power into the grid. The introduction of voltage source converters (VSC) in high-voltage high-power applications such as DC transmission, reactive power compensation devices and active power filtering devices, offer several features such as [5]:

1. Ability to provide voltage/reactive power support to the network.

2. Decoupling of the AC systems which results in improved fault ride-through capability.
3. Since power electronic converters are current control devices, they do not change significantly the fault level at the point of connection.

4. Facilitates connection of weak systems such as wind farm, independently of the effective short circuit ratio (ESCR).

5. Black start capability, this eliminates the need for the startup generator.

There are however, some disadvantages such as, inability to operate under unbalanced conditions and survive asymmetrical faults, vulnerability to DC faults, and the risk of system collapse in case of an open circuit at the terminal of the grid-side converter.

Features of VSC-HVDC transmission such as low space requirement, less visual impact, voltage support and independent control of active and reactive power have made the use of multi-terminal VSC-HVDC transmission more attractive for new expansions. Additionally, the VSC-HVDC multiterminal increases the control flexibility and improves reliability and stability of the AC power system as each AC system maintains its autonomy while exchanging the active power.

In reference [6], the authors have developed a control strategy that enables the use of multi-terminal VSC-HVDC for offshore wind farms integration. In this reference, the wind farm is represented by a coherent model of a variable speed wind turbine based on doubly fed induction generators (DFIG). To guarantee the power balance between the AC and DC sides, the AC voltage at the wind farm side is controlled such as to transfer to the grid all the power generated by the wind farm, without the need for an active power command. However, the authors assume constant frequency at the offshore network to facilitate the integration of DFIG-based wind turbines. In practice, this will require a start-up generator with significant power rating compared to the wind farm to set the reference frequency for the DFIGs. In [4] the authors presented a multiterminal VSC-HVDC system based on modular multilevel converters connecting two AC grids to improve the reliability 
and fault ride-through capabilities of the multi-terminal DC system. However, the paper only investigates the DC fault ridethrough capability and power management issues using droop control $\left(\mathrm{P}-\Delta \mathrm{V}_{\mathrm{dc}}\right)$.

In this paper, a multi-terminal DC network with four VSC stations is employed to transmit the power from two offshore wind farms to the grid. The main issues investigated are the control of the multi-terminal DC network to enable offshore wind power integration, power sharing strategy between the grid-side converters, AC fault ride-through capability issues, including the loss of one converter, and voltage and frequency support of the AC grid during major disturbances.

\section{System Outline}

Fig. 1 shows a four-terminal VSC HVDC transmission system connecting two identical offshore wind farms $\mathrm{WF}_{1}$ and $\mathrm{WF}_{2}$, each rated at $33 \mathrm{kV}, 700 \mathrm{MVA}$ based on FSIG wind turbines. The DC transmission system in Fig. 1 is arranged in bi-polar form to improve system resilience against single-pole to ground faults. Converters $\mathrm{VSC}_{1}$ through $\mathrm{VSC}_{4}$ are neutral pointclamped converters. The distance between the stations is $150 \mathrm{~km}$ and the transmission voltage is $\pm 150 \mathrm{kV}$. The ratings of the synchronous machines $\mathrm{SG}_{1}$ and $\mathrm{SG}_{2}$ are $33 \mathrm{kV}$ and $1400 \mathrm{MVA}$ at $50 \mathrm{~Hz}$. The total load demand is represented as a lumped static load connected to bus $\mathrm{B}_{9}$ as shown in Fig. 1.

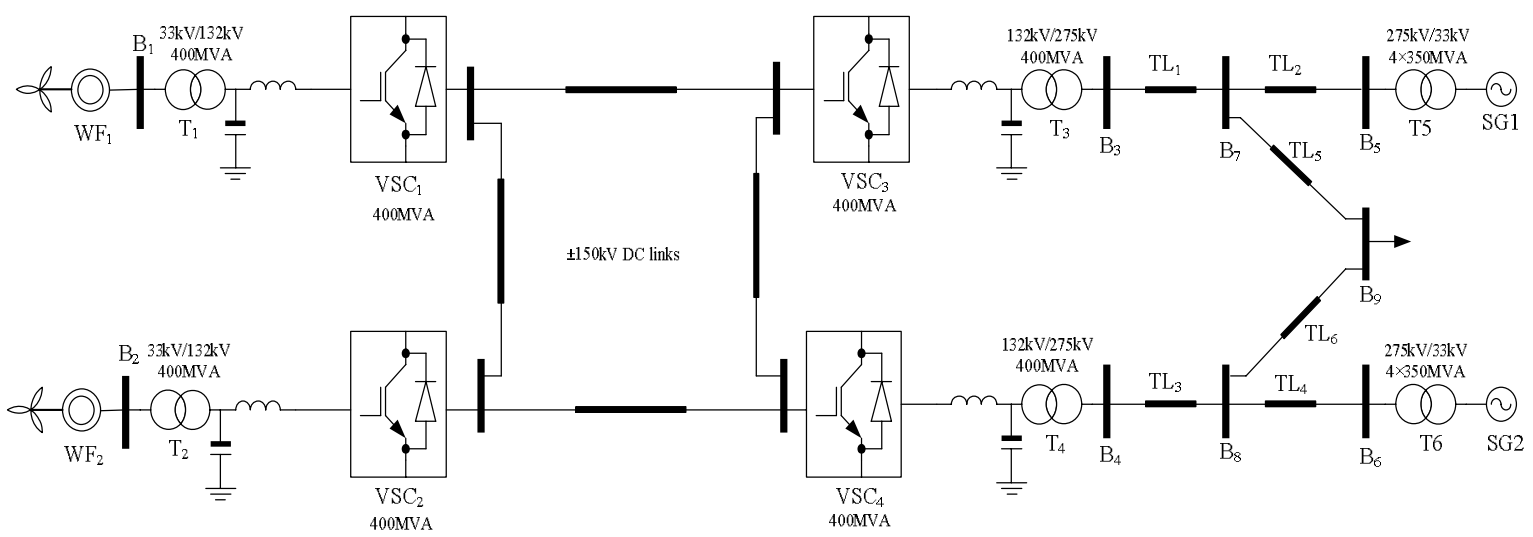

Fig. 1. Four-terminal DC transmission system based on voltage source connecting two offshore wind farms to the grid.

\section{System modelling}

\section{A. VSC-HVDC grid-side converter modelling and control}

The operation mode of the converters is chosen such that the grid-side converters $\left(\mathrm{VSC}_{3}, \mathrm{VSC}_{4}\right)$ regulate the $\mathrm{DC}$ link voltage at $300 \mathrm{kV}$ and maintain the $\mathrm{AC}$ voltage at the points of common coupling $\left(\mathrm{B}_{3}\right.$ and $\left.\mathrm{B}_{4}\right)$ at $1.0 \mathrm{pu}$. To facilitate the power sharing between the grid-side converters $\mathrm{VSC}_{3}$ and $\mathrm{VSC}_{4}$ by any ratio, a DC voltage droop controller is included in the DC voltage controller of converter $\mathrm{VSC}_{4}$. In this paper, all converters are controlled using vector control, where the d-axis is aligned with the voltage vector at the points of common coupling $\mathrm{B}_{1}$ through $\mathrm{B}_{4}$.

The decoupled control of active and reactive power is used. In this case, the active and reactive current components $i_{d 2}$ and $i_{q 2}$ control active and reactive power independently $\left(P=v_{d} i_{d}\right.$ and $\left.Q=-v_{d} i_{q}\right)$. The reference of the d-axis current $\left(i_{d 2}^{*}\right)$ and q-axis current $\left(i_{q 2}^{*}\right)$ are derived from the DC link and AC voltage controllers, respectively (and summarized in equation (1) and Fig. 2).

$$
\begin{aligned}
& i_{d 2}^{*}=k_{p 2}\left(V_{d c}^{*}-V_{d c}\right)+k_{i 2} \int\left(V_{d c}^{*}-V_{d c}\right) d t \\
& i_{q 2}^{*}=k_{p 3}\left(v_{2}^{*}-v_{2}\right)+k_{i 3} \int\left(v_{2}^{*}-v_{2}\right) d t
\end{aligned}
$$

Where $k_{p 2}, k_{i 2}, k_{p 3}, k_{i 3}$ are the proportional and integral gains of the DC voltage controller and the AC voltage controller, respectively. The gains of the inner loops must be selected much higher than the outer loop. The complete control system of the grid-side converters is shown in Fig. 2. The droop characteristic that enables the power sharing between the gridside converters is based on the DC link voltage (VDC) and the current flowing in the DC cable connecting $\mathrm{VSC}_{3}$ and $\mathrm{VSC}_{4}$ $\left(\mathrm{I}_{\mathrm{dc} 34}\right)$ as shown in Fig. 3.

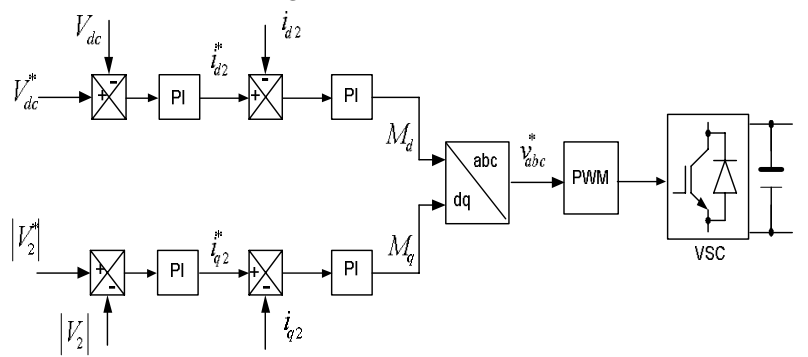

Fig. 2. VSC-HVDC grid-side converter control. 


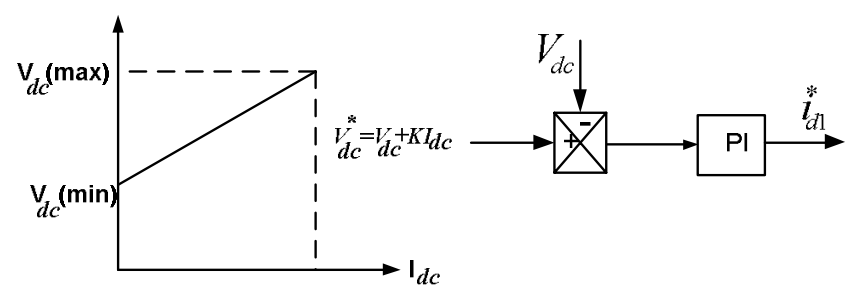

Fig. 3. DC droop controller and characteristic.

\section{B. VSC-HVDC wind farm side converter modelling and control}

Converter stations $\mathrm{VSC}_{1}$ and $\mathrm{VSC}_{2}$ are used to control the active power as in a conventional VSC-HVDC and to regulate the voltage at buses $\mathrm{B}_{1}$ and $\mathrm{B}_{2}$. According to equation (2) and Fig. 4, the reference current components $i_{d 1}^{*}$ and $i_{q 1}^{*}$ are derived from the active power controller and the AC voltage controller, respectively.

$i_{d 1}^{*}=\frac{P^{*}}{v_{d}}$

$i_{q 1}^{*}=k_{p 1}\left(v_{1}^{*}-v_{1}\right)+k_{i 1} \int\left(v_{1}^{*}-v_{1}\right) d t$

Where $k_{p 1}$ and $k_{i 1}$ are the proportional and integral gains of the AC voltage controller. To guarantee the correct power balance between the wind farm side and the DC side, independently of the wind speed, the active power controllers of converters $\mathrm{VSC}_{1}$ and $\mathrm{VSC}_{2}$ are equipped with supplementary frequency controllers. These frequency controllers maintain the power balance and provide short-term frequency regulation to the grid if any change happens in the generation-demand balance by utilizing the stored energy in the wind turbine inertia and the DC capacitors.

The frequency controllers are based on the active powerfrequency characteristic as in conventional synchronous generators [3], which can be represented by a linear equation as:

$$
f-f_{0}=K\left(P-P_{0}\right)
$$

According to equation (3), the change in power demand will affect system frequency, hence a PI controller is used to adjust the active power reference of converters $\mathrm{VSC}_{1}$ and $\mathrm{VSC}_{2}$ to regulate system frequency. The correction signal generated by the frequency controller can be expressed as:

$i_{c o r c}^{*}=k_{p 5}\left(f^{*}-f\right)+k_{i 5} \int\left(f^{*}-f\right) d t$

The complete control system block diagram of the wind farm side converter is shown in Fig. 4.

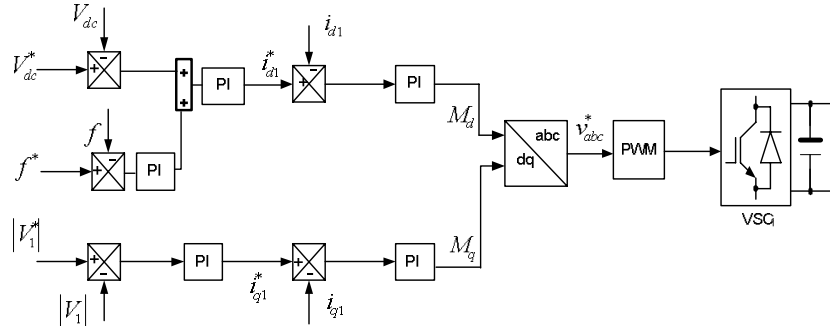

Fig. 4. Wind farm side converter control.

\section{Wind farm control}

The two wind farms are based on FSIG wind turbines. As the asynchronous generator consumes reactive power it is necessary to provide power factor correction capacitors at each wind turbine-generator. The wind turbine characteristic is defined as the relationship between the total captured power from the wind $\left(\mathrm{P}_{\mathrm{w}}\right)$ and the mechanical power going into the turbine rotor $\left(\mathrm{P}_{\text {mech }}\right)$ as described in equation $(5)$ :

$P_{\text {mech }}=c_{p} P_{\mathrm{w}}$

$P_{w}=k \cdot c_{p} \cdot v^{3}$

Where $v$ is the wind speed, $k$ is a constant and $\mathrm{c}_{\mathrm{p}}$ is the power coefficient. The value of $c_{p}$ is the function of $\lambda$ (the tip-speed ratio) and the blade angle $\beta$. The $c_{p}$ can be expressed as [1]:

$c_{p}=c_{1}\left(\frac{c_{2}}{\lambda_{i}}-c_{3} \beta-c_{4}\right) e^{\left(\frac{-c_{5}}{\lambda_{t}}\right)}+c_{6} \lambda$

The power extracted from the wind turbine can be controlled by adjusting the pitch angle $(\beta)$ in case of over speed. A simple PI controller is used to adjust the pitch angle by comparing the difference between the reference rotor speed $\omega_{r}^{*}$ and the measured rotor speed $(\omega)$ as shown in Fig. 5.

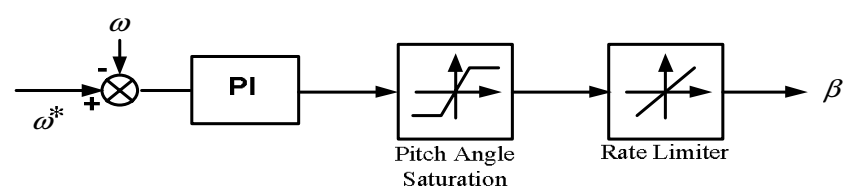

Fig. 5 control scheme of pitched regulated wind turbine

\section{Performance evaluation}

To assess the performance of the system in Fig. 1 regarding voltage and frequency support, fault ride-through capability and power management, the system is modelled in Simulink. The key case studies are:

- Frequency regulation of the AC grid and voltage support.

- Fault ride-through capability (three-phase fault). 
- Power management.

- Power sharing between the grid-side converters.

- Loss of the one grid side converter $\mathrm{VSC}_{4}$.

\section{Case I: Frequency support and voltage regulation}

As the active power balance in the power network is strongly coupled to the frequency, any mismatch between the generation and demand may cause the system frequency to rise or decrease, depending on the net difference between generation and demand. Similarly, voltage relates to the reactive power balance. The network sees any disturbance and fault as the increase or decrease in the active and reactive power demand and this must be addressed as fast as possible in order to maintain virtually constant voltage and frequency. Therefore, the faster response of the converter station of the VSC-HVDC, compared to conventional synchronous machines with relative large mechanical inertias, can be utilized to provide short-term frequency stabilization and continuous voltage support at the point of common coupling. To demonstrate the capability of the multi-terminal VSC-HVDC transmission system presented in Fig. 1 to provide the necessary voltage support and frequency stabilization to the grid, the load connected at bus $\mathrm{B}_{9}$ is reduced by $(80+j 60)$ MVA at time $t=15 \mathrm{~s}$. The results obtained from this case are shown in Fig. 6. It can be observed in Fig. 6a that the frequency has increased slightly and then it is stabilized at $50 \mathrm{~Hz}$ (nominal frequency) as the converters $\mathrm{VSC}_{3}$ and $\mathrm{VSC}_{4}$ reduce their output powers to match the new load demand (Fig. 6c) Also, the converters $\mathrm{VSC}_{3}$ and $\mathrm{VSC}_{4}$ adjust their reactive power exchange with the grid to maintain the reactive power balanced in order to maintain the voltage at the points of common coupling $\mathrm{B}_{3}$ and $\mathrm{B}_{4}$ at 1.0pu (nominal voltage) (Fig. 6c).

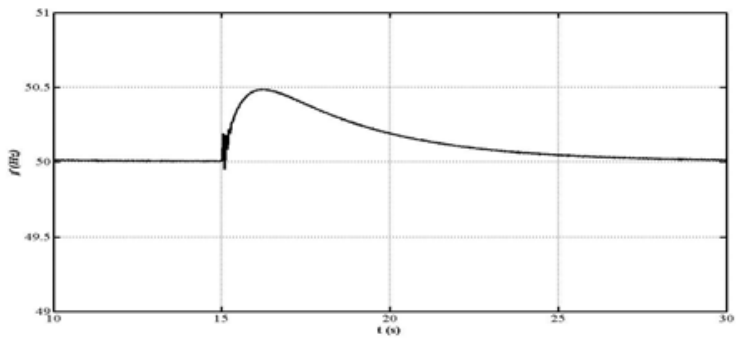

(a) AC network frequency

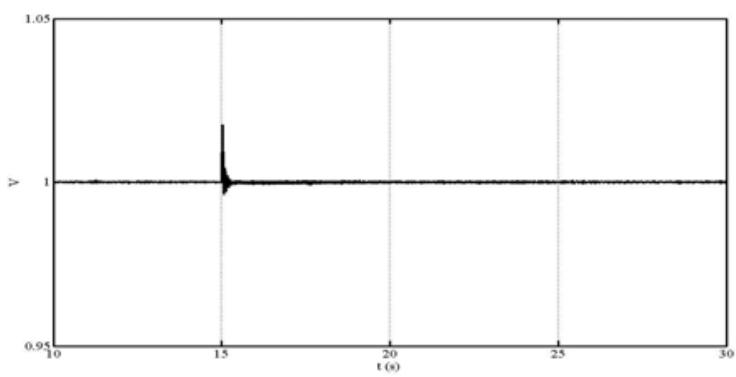

(b) Grid-side Voltage

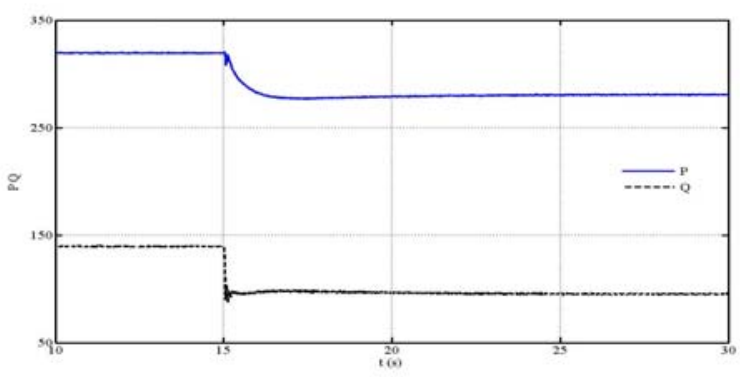

(c) Grid-side active and reactive power

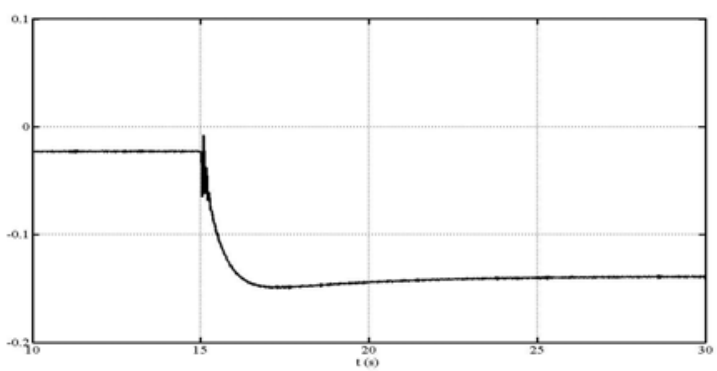

(d) Frequency controller correction signal

Fig. 6 Case I key simulation results (Frequency support and voltage regulation)

Case II: Fault ride-through capability (3-phase fault at $B_{3}$ )

To demonstrate the improved fault ride-through capability of the multi-terminal DC transmission system based on voltage source converters, the system in Fig. 1 is subjected to a threephase fault at bus $B_{3}$, with duration of $100 \mathrm{~ms}$ ( 5 cycles for $50 \mathrm{~Hz}$ ) at $\mathrm{t}=5 \mathrm{~s}$. Fig. 7 shows the key waveforms obtained. As expected the voltage at the wind farm side (busses $B_{1}$ and $B_{2}$ ) remains less sensitive to the $\mathrm{AC}$ fault in the grid (Fig. 7e). However, the DC link voltage of converter $\mathrm{VSC}_{3}$ increases during the fault period as a result of the trapped energy in the DC link (Fig. 7c). It can be observed that the voltage magnitude at bus $\mathrm{B}_{3}$ collapses during the fault period as the reactive power capability of the converter decreases (Fig. 7a). Despite the voltage collapse at $\mathrm{B}_{3}$, the converter $\mathrm{VSC}_{3}$ contributes limited current to the fault.

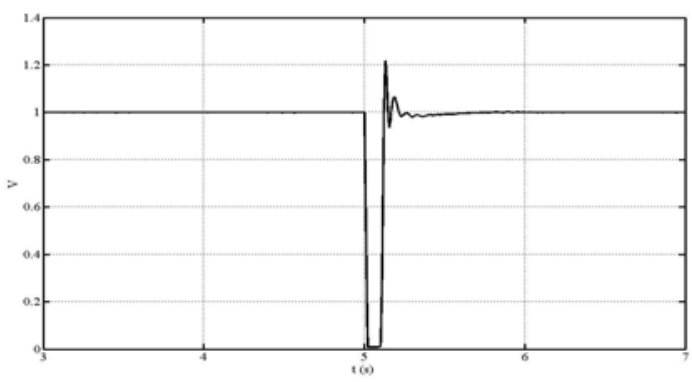

(a) Grid-side voltage 


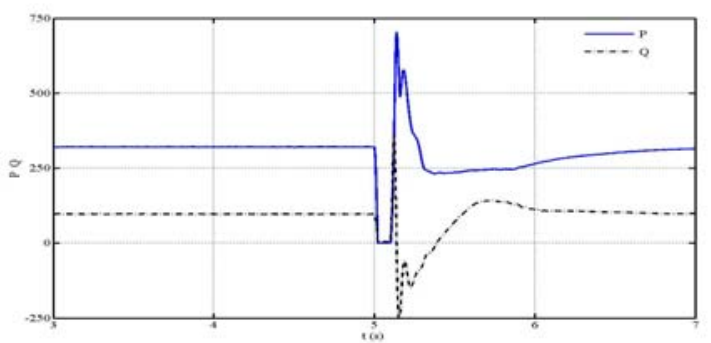

(b) Grid-side active power

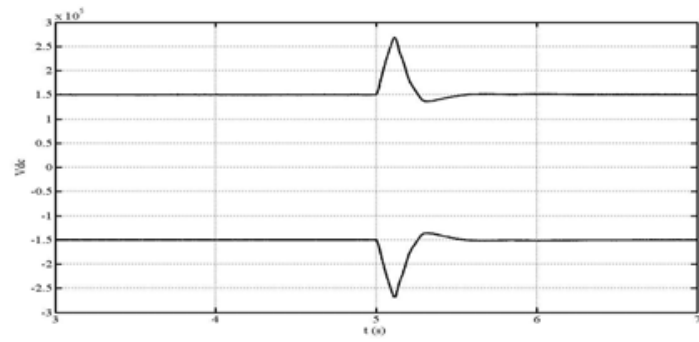

(c) DC link voltage

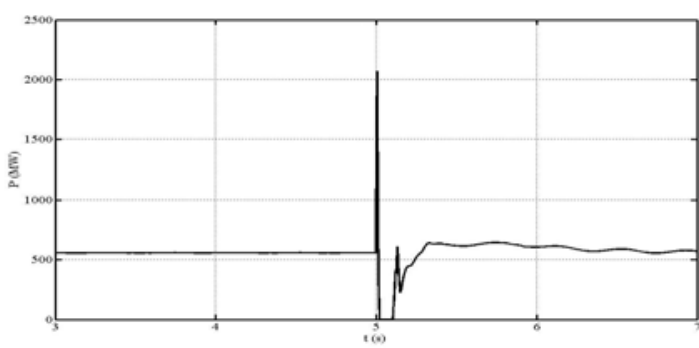

(d) Synchronous machine power

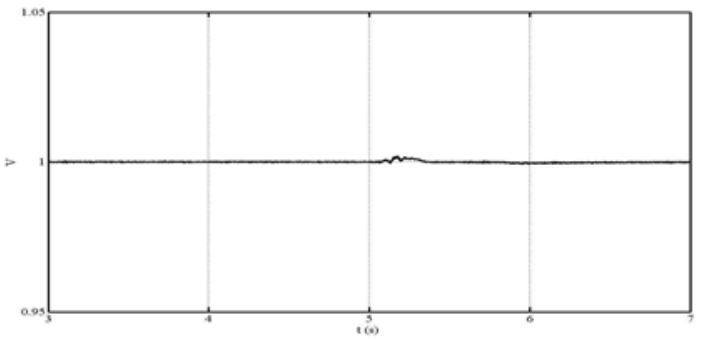

(e) Wind farm side voltage

Fig. 7 Case II key simulation results (Fault ride-through capability (3-phase fault at $\left.\mathrm{B}_{3}\right)$ )

Case III: power management and loss of grid side converter

Fig. 8 shows the active power sharing between the grid-side converters $\mathrm{VSC}_{3}$ and $\mathrm{VSC}_{4}$. At the start each converter injects $330 \mathrm{MW}$ of active power into the $\mathrm{AC}$ network at $\mathrm{B}_{3}$ and $\mathrm{B}_{4}$. It can be seen that that no power flows in the DC line connecting converters $\mathrm{VSC}_{3}$ and VSC4 in Fig. 1. At time $\mathrm{t}=2 \mathrm{~s}$, the droop control is activated to enable converter $\mathrm{VSC}_{3}$ to deliver $430 \mathrm{MW}$ into $\mathrm{B} 3$ and converter $\mathrm{VSC}_{4}$ delivers the remaining $230 \mathrm{MW}$ into $\mathrm{B}_{4}$. It can be observed that $100 \mathrm{MW}$ are flowing in the DC line between $\mathrm{VSC}_{3}$ and $\mathrm{VSC}_{4}$. At $\mathrm{t}=4 \mathrm{sec}$ the power command has been changed to inject 430MW through $\mathrm{VSC}_{4}$, and $230 \mathrm{MW}$ through converter $\mathrm{VSC}_{3}$. In this case, the power flow in the DC line between converters $\mathrm{VSC}_{3}$ and $\mathrm{VSC}_{4}$ is reversed. Fig. (8) shows that the power injected by converters VSC1 and VSC2 into the DC network remains constant at 340MW during the entire simulation period.

To show the potential benefits of using multi-terminal VSCHVDC transmission systems in terms of reliability and security of supply, the loss of one grid-side converter is investigated. Fig. 9 shows the results obtained during temporary loss of converter VSC4. In this case, converter $\mathrm{VSC}_{4}$ is deliberately disconnected at $\mathrm{t}=2 \mathrm{~s}$ and reconnected at $\mathrm{t}=4 \mathrm{~s}$. It can be observed that during the loss of converter $\mathrm{VSC}_{4}$, all the power is delivered to the grid through the converter $\mathrm{VSC}_{3}$. To make this case possible, the rating of the converters $\mathrm{VSC}_{3}$ and $\mathrm{VSC}_{4}$ are increased to twice that of $\mathrm{VSC}_{1}$ and $\mathrm{VSC}_{2}$ in order to be able to carry the full power from the wind farm in case of loss of one of the grid converter.

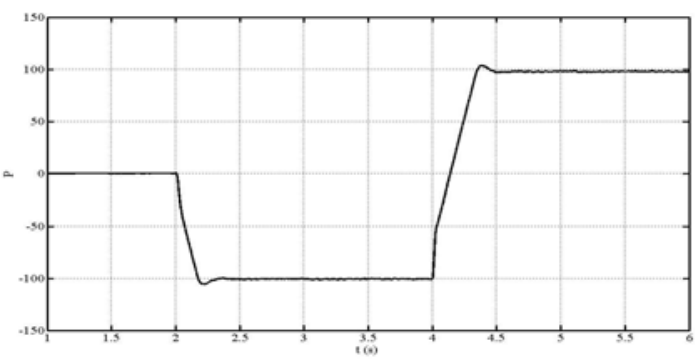

(a) Active power at auxiliary cable

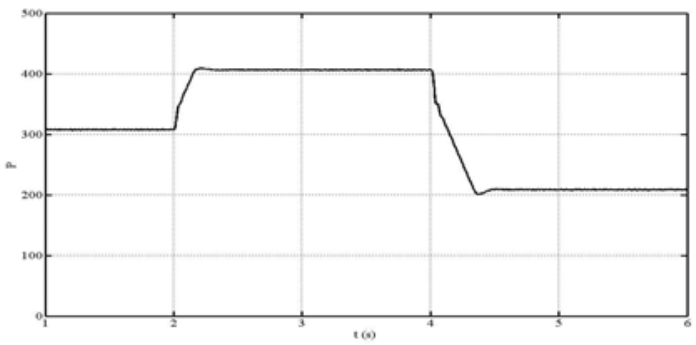

(b) Active power at grid-side converter $\left(\mathrm{VSC}_{3}\right)$

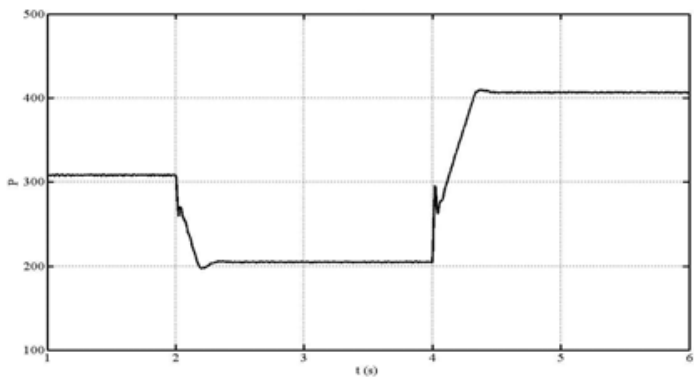

(c) Wind farm side converter control ( $\left.\mathrm{VSC}_{4}\right)$ 


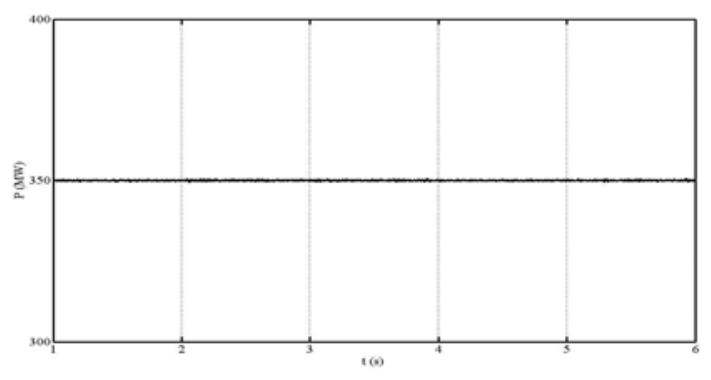

(d) Wind farm side converter Control

Fig. 8 Case III simulation result (power management)

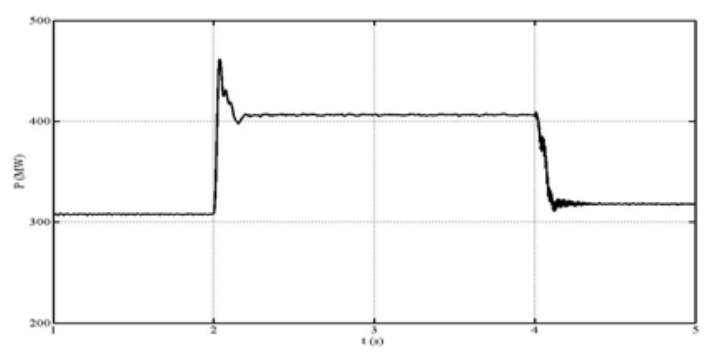

(a) Active power at grid-side converter (VSC3)

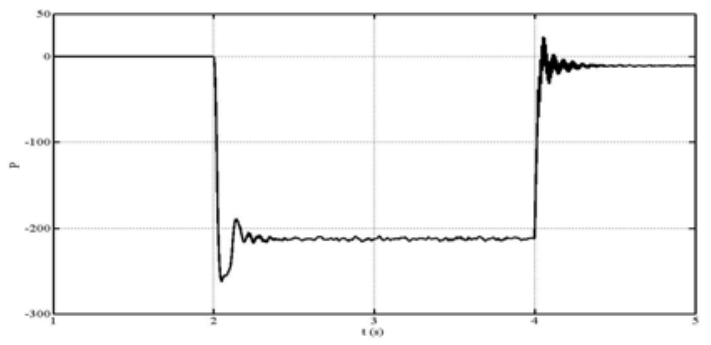

(b) Active power at grid-side converter (VSC4)

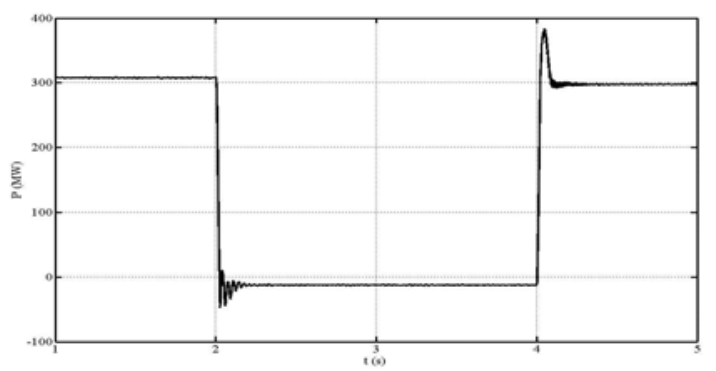

(c) Active power at auxiliary cable

Fig. 9 Case III simulation result (loss of grid side converter)

\section{Conclusions}

This paper discussed the application of a multi-terminal DC network to transfer power from two offshore wind farms to the grid. It was found that found that the use of multi-terminal DC transmission system may improve system reliability against loss of a converter, it may also allow the improvement of transient stability as the converter stations are able to remain connected to the grid during the entire fault period in the grid side as long as it takes, providing reactive power support without increasing the risk of converters failure if proper current control is in place.

\section{References}

[1]. Ackermann T, "Wind Power in Power System", John Wiley \& Sons.Ltd, 2005.

[2]. Arrillaga.J, Liu Y.H.L and Watson N.R," Flexible Power Transmission-The HVDC Options", John Wiley \& Sons, Publication, 2007

[3]. Du C, Bollen M.H.J,"Power-frequency control for VSCHVDC during island operation", The 8th IEE International conference on $\mathrm{AC}$ and $\mathrm{DC}$ Power Transmission, 2006. ACDC 2006. March 2006.

[4]. Grain.P.A, Olimpo.A. L, and Burt G" Multi-Terminal DC Transmission System based on modular multilevel converter", the $44^{\text {th }}$ international universities Power Engineering Conference, UPEC 2009.

[5]. Guangkai Li, Gengyin Li, Liang Haifeng and Yin Ming,' Research on hybrid HVDC', International Conference on Power System Technology, PowerCon 2004.

[6]. Lie Xu, Williams B.w and Liangzhong, "Multi-Terminal DC Transmission Systems for Connection Large Offshore Wind Farms", Power and Energy Society General Meeting - Conversion and Delivery of Electrical Energy in the 21st Century, 2008 IEEE.

[7]. lov F, Teodorescu R, Blaabjerg F, Andersen B, Birk $\mathrm{J}$ and Miranda $\mathrm{J}$,"Grid Code Compliance of Grid-Side Converter in Wind Turbine Systems", Power Electronics Specialists Conference, 2006. PESC 06. 37th IEEE, June 2006.

[8]. Prabha Kundur,"Power System Stability and Control", Mc-Hill, Inc, New York, 1994.

[9]. Stephan Meier," Novel Voltage Source Converter based HVDC Transmission System for Offshore Wind Farms", PhD Thesis, Royal Institute of Technology, Stockholm 2005.

[10]. Szabo, L, Biro K.A, Nicula C and Jurca, F ''Simulation of Wind Turbine Driven Autonomous Squirrel Cage Induction Generators', Intelligent Engineering Systems, 2007. INES 2007. 11th International Conference.

[11]. Thomas J. L, Poullain S, and Benchaib A., "Analysis of a Robust DC Bus Voltage Control System for a VSC Transmission Scheme", Conference of the 7th AC/DC Transmission, Nov. 2001.

[12]. Yazdani, A. Iravani R." Dynamic model and control of the NPC-based back-to-back HVDC system", Power Delivery, IEEE Transactions, Jan 2006, Volume 21, Page 414-424. 